\title{
LA-ICP-MS Signal Enhancement by Hydrogen Gas Addition to Carrier Gasfor the Analysis of Ultra-trace Elements in Olivine and Orthopyroxene
}

\author{
MARINA VETER ${ }^{1}$, OLIVIER ALARD ${ }^{1,2}$ AND STEPHEN F. \\ FOLEY ${ }^{1}$ \\ ${ }^{1}$ Macquarie University \\ ${ }^{2}$ Université Montpellier \\ Presenting Author: marina.veter@mq.edu.au
}

Investigation of the Earth's geochemical composition and understanding of its evolution has been a major focus of research for many decades. The upper mantle has been well characterized in its major and minor element composition, and it is established that the silicate phases clinopyroxene and garnet are the major hosts for trace elements in the upper mantle. However, these minerals may be completely consumed in highly depleted peridotites, particularly in Archean lithosphere, leaving olivine and orthopyroxene as the main repositories for trace elements in mantle rocks.

This study focused on the optimisation of the widely used in situ LA-ICP-MS method to enable the acquisition of low-level trace elements in the residual minerals olivine and orthopyroxene. The measured elements were extended to a palette of 72 masses, including many low-level ultra-trace elements with concentrations close to or below detection limits, and so are underrepresented in studies of olivine, orthopyroxene and the bulk mantle. These include particularly REEs and volatile chalcophile and siderophile elements. These analytical limitations were addressed by the addition of molecular hydrogen gas $\left(5 \mathrm{~mL} \mathrm{~min}^{-1}\right)$ to the carrier gas flow and compared with the standard method (no hydrogen). Our results show a clear improvement in sensitivity on certified reference material (CRM) glasses NIST 612 and BCR-2G. The sensitivity enhancement is more pronounced for elements showing high first ionisation energy such as $\mathrm{Zn}$, As and $\mathrm{Cd}$. This suggests that addition of trace amount of $\mathrm{H}_{2}$ increase plasma temperature and thus ionisation efficiency. Further, the precision of measurements, expressed as RSD\%, improves from $3-16$ to $2-6 \%$ on CRM. Analyses of natural olivine demonstrate improvements in precision (e.g., RSD \% for Ga from 68 to $34 \%$ ) and the limit of detection (improved LOD ranges for e.g., $\mathrm{Cu}$ from 6-10 to 4-6 $\mathrm{ng} \mathrm{g}^{-1}, \mathrm{Nd}$ from $1-2$ to $\left.0.6-1.0 \mathrm{ng} \mathrm{g}^{-1}\right)$. These advances facilitate the acquisition of complete REE patterns for natural olivines. Furthermore, the volatile chalcophile and siderophile group of elements, e.g., Mo, Cd, In are now accessible at ng $\mathrm{g}^{-1}$ concentration levels with more precision. 